\title{
An Oscillatory Shear Index-based Model to Describe Progressive Carotid Artery Stenosis
}

\author{
P Patalano $\mathrm{MD}^{a * *}$ \\ ${ }^{a}$ New York University Medical Center, 530 1st Ave., New York, NY 10016
}

\section{ARTICLE INFO}

\section{Keywords:}

carotid atherosclerosis

computational biology

computational fluid dynamics

hemodynamics

modeling

oscillatory shear index

\begin{abstract}
A B S T R ACT
Background and aims: This study describes and demonstrates the applicability of a novel in silico method for modeling progressive carotid artery stenosis using the oscillatory shear index (OSI) as the basis of stenosis function. Methods: Three-dimensional reconstructions of 11 carotid arteries were generated using patient-derived magnetic resonance angiography and duplex ultrasound data. Computational fluid dynamic simulations were sequentially performed following computational stenosis assessment, and corresponding changes in OSI were observed and used as measure of morphological stabilization. Results: Six carotid models showed progressive stenosis with statistically significant increases in regions of high OSI (OSI $>0.2, p<0.05)$ with eventual carotid occlusion in one of the cases. Three models remained free or nearly free of increased OSI, whereas one model showed an overall decrease in high OSI regions $(p<0.05)$ and another trended in that direction but did not achieve statistical significance $(p=0.145)$. Conclusions: To our knowledge, this is the first computational model describing progressive stenosis in any peripheral artery including the carotid. Taken together, this study provides a novel framework for computational hemodynamic investigations on progressive atherosclerosis in the carotid artery.
\end{abstract}

\section{Introduction}

Atherosclerotic plaques near the carotid bifurcation, particularly in the internal carotid artery (ICA), are believed to be the most common detectable cause of ischemic stroke. When classified as high-grade, asymptomatic patients have 4.6-18.5\% risk of experiencing stroke within 5 years [1]. Carotid endarterectomy and stenting are common treatment options for symptomatic and severe asymptomatic carotid artery stenosis [2]. Although progression of stenosis (regardless of treatment) cannot be reliably predicted, it remains a clinically relevant problem. Hemodynamic factors related to low wall shear stresses (WSSs) have been implicated in the development of atherosclerosis within the carotid artery $[3,4,5]$. However, it is still difficult to predict which patients will progress and which will stabilize, as the available approaches are based on catch-all efforts to monitor patients with moderate stenotic lesions using repeated imaging data.

WSS, which describe the forces acting in parallel to the vessel wall, is a well-studied factor involved in the genesis of atherosclerotic plaques in the arterial system. Areas of high WSS tend to result from highly organized laminar flow, whereas areas of low WSS tend to be characterized by complex flow patterns (including oscillatory flows). Low WSS has been implicated in the activation and deactivation of inflammatory pathway genes that, when left unchecked, result in the triggering of the atherosclerotic cascade in both in vitro and in vivo studies $[6,7,8,9]$.

In this study we describe and validate a novel in silico method for modeling atherosclerotic progression.

${ }^{*}$ Corresponding author

peter.patalano@nyulangone.org (P. Patalano)

www. arch-lab.org, info@arch-lab.org (P. Patalano)

ORCID(s):
Framing questions concerning aberrant fluid patterns has pave the way for investigations aiming to test numerical and computational methods for a better understanding of this problem. Using computational fluid dynamic (CFD) approaches and the finite element method (FEM), it became possible to model complex fluid flows in the arterial lumen by reconstructing three-dimensional (3D) models from imaging data, such as computer tomographic angiography (CTA) and magnetic resonance angiography (MRA). Additionally velocometric data can also be obtained from duplex ultrasound (DUS) and certain MR sequences, which can also aid the modeling and simulation process $[10,11]$.

Although WWS metrics were reported to be strongly associated to the initiation and propagation of atherosclerotic plaques, spatial prediction of plaque development remains difficult, owing partially to challenges in reproducibility [12, 13]. Prior studies have focused on correlations between WSS and the spatial location of the plaques; however, the hemodynamic effects of modeled stenosis may have on future CFD simulations remains unclear. Hence, this approach provides only a static picture of the development and progression of atherosclerosis.

The present study explores the hemodynamic changes that are induced by modeled stenosis to generate a model for atherosclerosis progression. A dynamic modeling approach was used for a better understanding of the effects of in silico stenosis on future hemodynamics and subsequent progression of stenosis. The problem was addressed in an iterative manner, where flow in a native artery was simulated and stenosis was generated according to the corresponding OSI. This process was repeated, while considering any hemodynamic changes induced by in silico stenosis generated by previous simulations. Thus, rather than attempting to predict point-based atherosclerosis, the proposed new method focuses on the effect of in silico stenosis on future 
bioRxiv preprint doi: https://doi.org/10.1101/2022.02.04.479106; this version posted February 6, 2022. The copyright holder for this preprint (which was not certified by peer review) is the author/funder, who has granted bioRxiv a license to display the preprint in perpetuity. It is made available under aCC-BY-NC-ND 4.0 International license.

\section{An OSI-based Model To Assess Carotid Artery Stenosis}

hemodynamics and subsequent changes in OSI. A central question raises of whether stenosis in a region of high OSI leads to more favorable or less favorable hemodynamics in future CFD simulations. The luminal surface was treated as a changing landscape, as new stenoses arise, the flow of fluid through the lumen is necessarily changed. The question can then be rephrased - does in silico stenosis serve to stabilize or destabilize future flows?

\section{Theory}

Blood flow in the human carotid artery is governed by the physical properties of the fluid (i.e. viscosity, density, among other characteristics), the applied force that acts on it (i.e. heart), and the boundaries with which the blood interacts (i.e. vessel walls). As with all other fluids, blood flow is governed by the principles of mass, momentum, and energy conservation, which are in turn physical laws that can be represented by the incompressible Navier-Stokes equations, which describe viscous fluid flow in 3D. (Eq. 1).

$$
\rho \frac{D \mathbf{V}}{D t}=-\nabla p+\mu \nabla^{2} \mathbf{V}, \quad \nabla \cdot \mathbf{V}=0
$$

Equation 1 states that the acceleration in a fluid is equal to the sum of the pressure forces $(-\nabla p)$ and the viscous diffusing forces $\left(\mu \nabla^{2} \mathbf{V}\right)$. Additionally, in the incompressible form, the continuity relationship $(\nabla \cdot \mathbf{V}=0)$ shows that the amount of fluid that flows into a volume must be equal to the amount that flows out. Solving this system of partial differential equations allows to understand the velocity and trajectory of blood within an artery, as well as the forces that are imparted by the fluid on the vessel walls. These principles are often applied experimentally to determine the stability of implanted devices, as well as to better understand the effects of complex flows on the vascular biology and gene expression related to pathological processes, such as atherosclerosis and aneurysm formation [14, 15, 16, 17, 18]. Experimental research in medicine and bioengineering have led to the discovery of certain complex flows that serve as the initiators and propagators of both aneurysms and atherosclerotic disease [19, 7, 8, 20]. Of specific interest to our work are flows that result in layer separation and oscillatory patterns at the carotid artery bifurcation. Since these flow patterns and related WSS have been implicated in atherosclerosis, being able to model and quantify flows in this region may have important implications in the prediction of atherosclerotic plaque formation and progression of clinically significant stenosis.

Low and oscillatory wall stresses in animal models lead to gene expression, which facilitates the cascade of vessel wall inflammation, endothelial proliferation, apoptosis, permeability, and cholesterol deposition. Similar observations have been made in clinical studies. Indeed, oscillatory flow patterns in particular have been implicated in the progression of atherosclerosis [21, 12].

Various indices have been numerically developed and experimentally verified to quantify these stresses and their

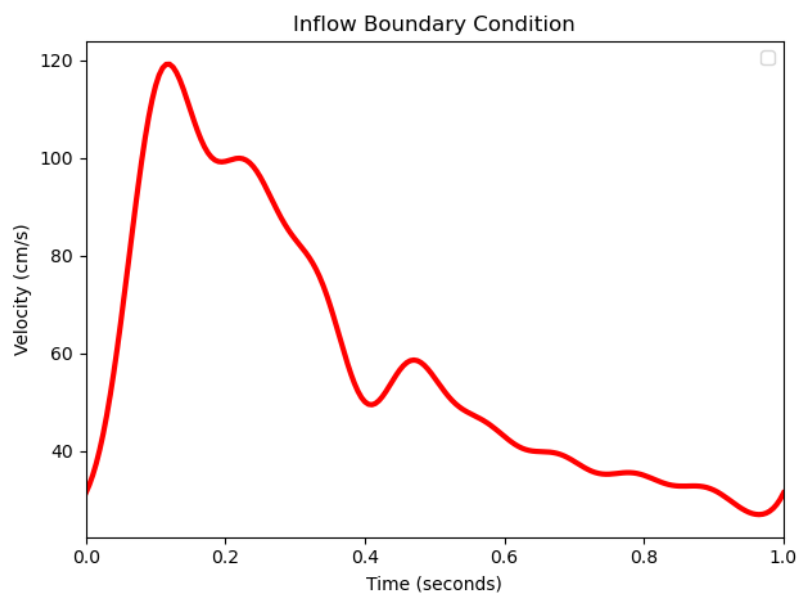

Figure 1: Example of the inflow boundary condition used for computational fluid dynamic simulations. Peak systolic velocity (PSV) is obtained from duplex ultrasound (DUS) data and the waveform is estimated using the feature points seen in the human common carotid waveform [25].

associated flow patterns. The one we found most useful was the OSI, owing its association with plaque progression in clinical studies $[22,23]$. At any given point on the luminal surface, for a given time period, OSI (Eq. 2) quantifies how much wall shear stress deviates from the average value at that point. Hence, OSI can describe whether flow at a certain point tends to be laminar and simple $(\mathrm{OSI}=0)$ or if it is subjected to maximal amounts of flow reversal $(\mathrm{OSI}=0.5)$ [24]. This index was used as the basis of a new in silico stenosis model.

$$
O S I=\frac{1}{2}\left(1-\frac{\left|\int_{0}^{T} \tau_{\omega} d t\right|}{\int_{0}^{T}\left|\tau_{\omega}\right| d t}\right) \quad \text { where, } \tau_{\omega}=\mu \frac{d u}{d y}
$$

To account for the effects of pulsatile flow on complex flow patterns, we used a strategy of pulsatile waveform estimation based on velocity data obtained from clinical DUS. Moreover, feature points described by Hoi et. al. [25] were used to estimate velocity based on DUS peak systolic velocity (PSV) data. We considered an end diastolic velocity (EDV) within $10 \mathrm{~cm} \cdot \mathrm{s}^{-1}$ to be acceptable. The waveform was then interpolated using Fourier smoothing, resulting in a patient-specific waveform estimation to be used in CFD simulation (Figure 1).

After running the fluid dynamic simulation for sufficient time to achieve flow stabilization, OSI was calculated across the luminal surface. Each element $\left(\mathbf{P}_{\mathbf{i}}\right)$ on the vessel lumen was then translated by the magnitude of the corresponding $O S I_{i}$ in the direction of the inward facing the normal surface $\left(\hat{\mathbf{P}}_{\mathbf{i}}\right)($ Fig. 2), resulting in a novel luminal surface and in silico stenosis. Fluid dynamic simulation was then repeated on the novel surface and observed visually for new areas of high OSI. 
bioRxiv preprint doi: https://doi.org/10.1101/2022.02.04.479106; this version posted February 6, 2022. The copyright holder for this preprint (which was not certified by peer review) is the author/funder, who has granted bioRxiv a license to display the preprint in perpetuity. It is made available under aCC-BY-NC-ND 4.0 International license.

\section{An OSI-based Model To Assess Carotid Artery Stenosis}

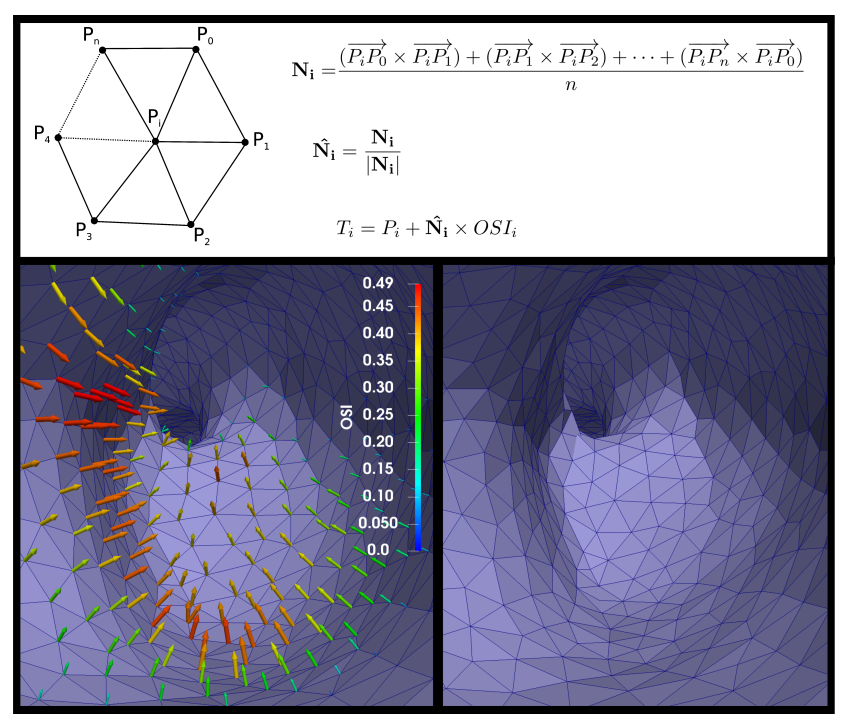

Figure 2: The top panel describes the stenosis generation process. In the normal stage, $\mathbf{N}_{\mathbf{i}}$ is calculated for a given point $\left(P_{i}\right)$ by averaging the normal conditions of the adjacent faces. The normal unit $\hat{\mathbf{N}}_{\mathbf{i}}$ is then calculated. The translation $T_{i}$ is then performed by moving the point $P_{i}$ in the direction of the normal by the magnitude of OSI. The bottom panels graphically demonstrate the process of stenosis generation. In the bottom left panel, each glyph represents the inward facing normal unit multiplied by the OSI. The bottom right panel shows the stenosis after the translation is completed.

It was our hypothesis that at least two situations could emerge after each CFD simulation and the in silico stenosis function was performed:

(1) the stenosis function could lead to stabilization of OSI, resulting in less stenosis on subsequent simulations, or

(2) the stenosis function could lead to new areas of high OSI, propagating the stenosis on subsequent simulations.

Should situation (1) occur, subsequent analyses would yield no meaningful stenoses, whereas in situation (2), the stenosis would propagate until situation (1) was encountered or the luminal surface arrives in apposition, i.e., an occlusion occurs. Thus, this iterative process can be used to model patient-specific progression of stenosis, a technique which may have both experimental and clinical applications in the future.

\section{Patients and methods}

This study was conducted under the guidance of the NYU School of Medicine Institutional Review Board. MRA and DUS data were obtained from the medical record of patients being followed for suspected carotid artery stenosis. Patients were included if an MRA and DUS of the carotid arteries were obtained at the time of initial consultation. All studies were made anonymous after acquisition to protect patient information.
Patient imaging data was first anonymized and assigned a random 3 digit ID number. DICOM images were loaded into the Vascular Modeling Toolkit (VMTK, http://www.vmtk.org) and image segmentation was performed using built-in semiautomatic methods (colliding fronts and fast marching algorithms). 3D surfaces were obtained using implementation of the marching cubes algorithm of the VMTK. The surfaces were then clipped and flow extensions were added to the common carotid artery (CCA), ICA, and external carotid artery (ECA). The bounding boxes used to clip the branches were stored as multi-block surfaces. 3D surfaces were converted into polygonal meshes using SimVascular (SV, http://www.simvascular.org) with increased density of elements at the boundary wall.

Due to the lack of detailed velocity data over the cardiac cycle in the CCA, a pulsatile waveform estimation was performed. PSV at the CCA was first obtained from DUS. Additional points were then generated based on the relative amplitude of feature points seen in the CCA waveform in older adults. The estimated EDV obtained by this method was then compared with DUS data. We arbitrarily chose a difference of $10 \mathrm{~cm} \cdot \mathrm{s}^{-1}$ between estimated and observed EDV to be acceptable. Using the built-in Fourier estimation of SV, the inlet velocity based pulsatile waveform was then generated.

In individual models, pulsatile blood flow was simulated. The arterial wall was assumed to be rigid. Blood was assumed to be an incompressible, Newtonian fluid with density $\rho=1.06 \mathrm{~g} \cdot \mathrm{cm}^{-} 3$ and viscosity $\mu=0.004 \mathrm{~Pa} \cdot \mathrm{s}$. The fluid dynamic solver from SV was used for fluid flow simulations and was solved using the High Performance Computing cluster at NYU. At the inlet boundary, we simulated velocitybased pulsatile flow with a parabolic velocity profile. Initial velocity during the cardiac cycle was estimated based on the waveform feature points, as above described, and based on patient-specific clinical DUS PSV at the CCA. Resistance boundary conditions were used at the outlets. Other boundary conditions included rigid-walls and zero-slip. The simulation was run for a total of six cardiac cycles based on the baseline heart rate of the patient. A total of 200 time points per each cardiac cycle were simulated.

Following CFD simulation, the stenosis function was performed using ParaView (http://www.paraview.org) and our own code written in Python using the VMTK and VTK packages. First, flow extensions were removed using the previously stored clipping box data. Next, inward facing normal units were generated at each point on the polygonal dataset and point-wise translation was performed (Figure 2). The resulting stenosis was first visually verified, then quantified based on the stability of OSI. To assess for OSI stability following each iteration of stenosis, the variance of the OSI was calculated across the luminal surface and was compared with subsequent runs using Levene's test. We considered a $p$-value of $<0.05$ to be statistically significant. We chose an OSI cutoff of $>0.2$ to be considered high, based on previous reports showing increased risk of atherosclerosis for OSI between 0.1 and 0.3 [26, 27, 28]. 
bioRxiv preprint doi: https://doi.org/10.1101/2022.02.04.479106; this version posted February 6, 2022. The copyright holder for this preprint (which was not certified by peer review) is the author/funder, who has granted bioRxiv a license to display the preprint in perpetuity. It is made available under aCC-BY-NC-ND 4.0 International license.

\section{An OSI-based Model To Assess Carotid Artery Stenosis}

Table 1

Baseline characteristics from patient-derived data including the reported stenosis percent as recorded with duplex ultrasonography. EDV (est.) is the EDV which was used in the pulsatile waveform for simulation approximated with pulse waveform estimation.

\begin{tabular}{llllllllll}
\hline \multirow{2}{*}{ ID } & Age & Sex & Laterality & HR & PSV (US) & EDV (US) & EDV (est.) & $\Delta$ EDV & Pct. Stenosis \\
\hline c696 & 68 & M & L & 60 & 115 & 24 & 24.15 & -0.15 & $50-79 \%$ NASCET \\
c284 & 65 & M & L & 60 & 133 & 22 & 27.93 & -5.93 & $16-49 \%$ NASCET \\
c704 & 66 & M & L & 81 & 79 & 22 & 16.59 & 5.41 & $16-49 \%$ NASCET \\
c484 & 66 & M & R & 81 & 76 & 16 & 15.96 & 0.04 & $50-79 \%$ NASCET \\
c621 & 84 & F & L & 65 & 54 & 7 & 11.34 & -4.34 & $50-79 \%$ NASCET \\
c992 & 84 & F & R & 65 & 70 & 6 & 14.7 & -8.70 & $16-49 \%$ NASCET \\
c471 & 53 & M & L & 72 & 99 & 27 & 20.79 & 6.21 & normal \\
c166 & 53 & M & R & 72 & 107 & 28 & 22.47 & 5.53 & normal \\
c181 & 55 & M & L & 78 & 107 & 14 & 22.47 & -8.47 & $<50 \%$ SRU \\
c612 & 55 & M & R & 78 & 120 & 20 & 25.2 & -5.20 & $<50 \%$ SRU \\
c624 & 83 & M & R & 65 & 57 & 20 & 11.97 & 8.03 & $50-79 \%$ NASCET \\
\hline
\end{tabular}

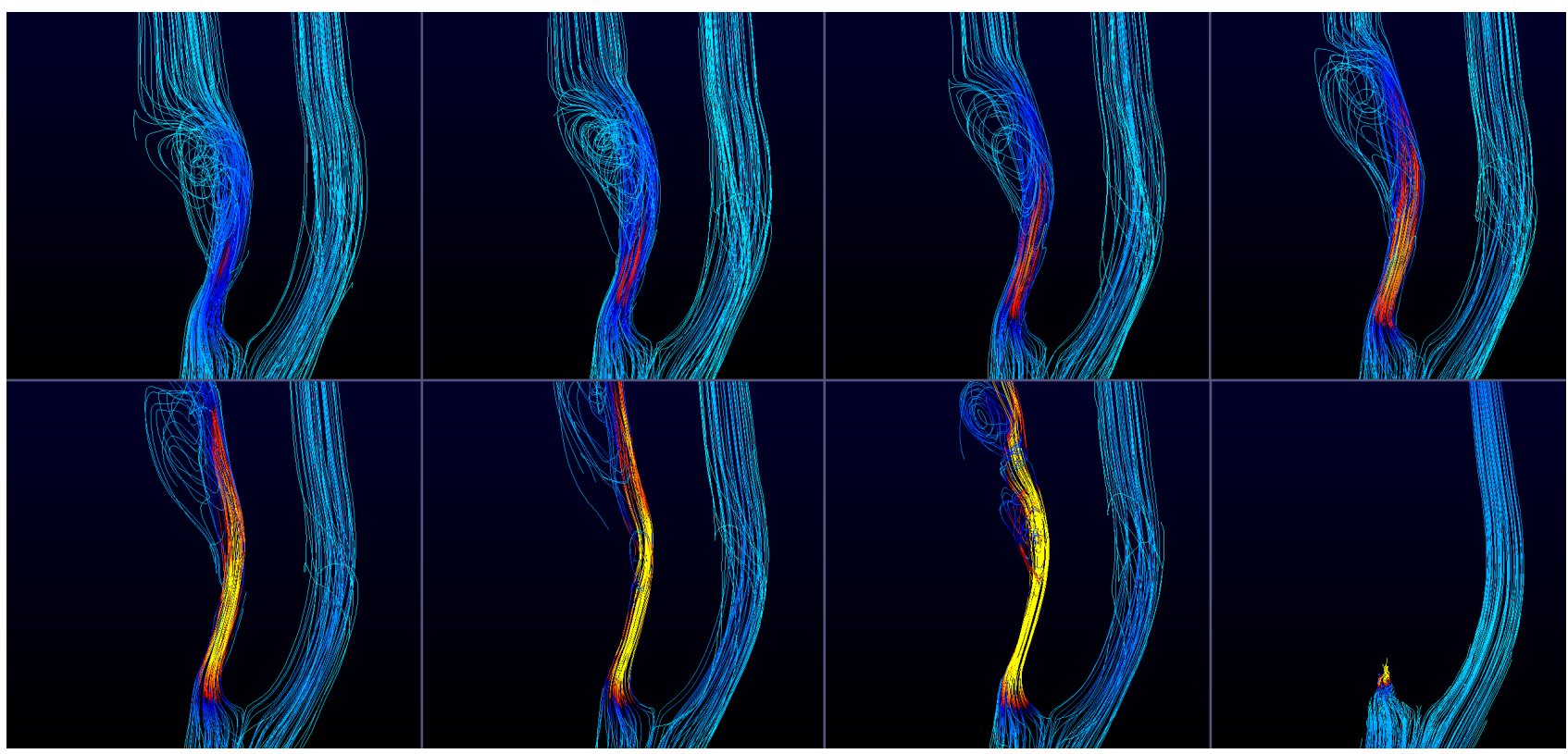

Figure 3: A particle trace in sequential simulations and stenoses in model c624. Cooler and warmer colors represent lower and higher relative velocities, respectively. The top left panel (A) represents the computational fluid dynamic simulation based on the native magnetic resonance imaging geometry. Early stages of the stenosis progression process is shown in the (B), (C), and (D). (E), (F) and (G) further show that the stenosis continues to worsen and leads to a total occlusion $(H)$ at the early internal carotid artery.

\section{Results}

The build models were visually inspected between simulations and obvious luminal narrowing was noted, especially in those with relatively large variance of OSI. As expected, each carotid model deformed to a certain degree with each subsequent simulation. However, two broadly discernible patterns emerged from these observations.

It was noted that the distribution of OSI could change in the vessel lumen without creating regions of high OSI (OSI $>0.2$ ), as observed in c181 (Figure 2, panel 1). The variance of OSI across the luminal surface showed a statistically significant increase ( $p<<0.001$ ), from 0.000394 to 0.000592 , without introducing regions of high OSI. A similar case arose in model c612 (Figure 2, panel 4), which showed a statistically significant increase in variance without generating regions of high OSI ( $p<<0.001)$, which seemed to be similar to the first three simulations in c704 (Figure 2, panel 7). However, in the final simulation, $0.19 \%$ (Table 2 ) of the luminal surface was found to have an OSI $>0.2(p \approx 0)$.

After a single simulation, the morphological changes in c624 were drastic enough to warrant further investigations (Figure 4). Three more simulations were run and the analysis failed due to complete lack of flow at the internal carotid outlet in the final simulation, representing a total occlusion of the early ICA.

A modest increase $(<1 \%)$ in high OSI regions was observed in c992 (3.09\% to $3.46 \%, p=2.42 e-6)$, c471 
bioRxiv preprint doi: https://doi.org/10.1101/2022.02.04.479106; this version posted February 6, 2022. The copyright holder for this preprint (which was not certified by peer review) is the author/funder, who has granted bioRxiv a license to display the preprint in perpetuity. It is made available under aCC-BY-NC-ND 4.0 International license.

An OSI-based Model To Assess Carotid Artery Stenosis

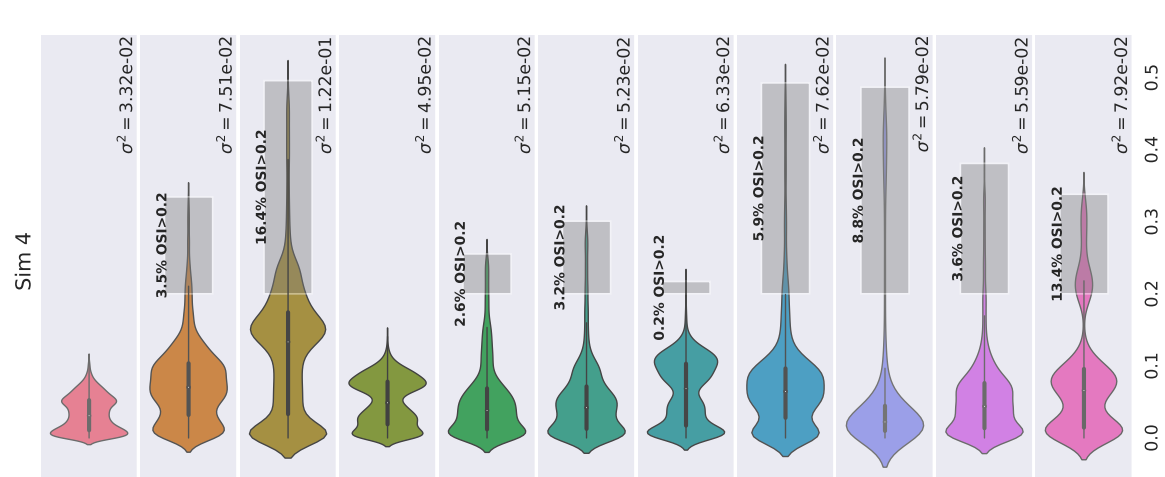

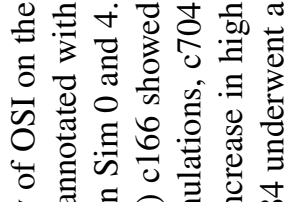

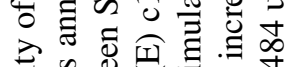
穿. 离

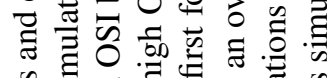

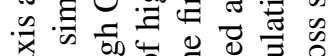

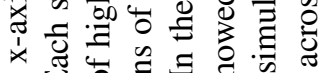

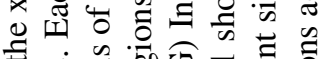

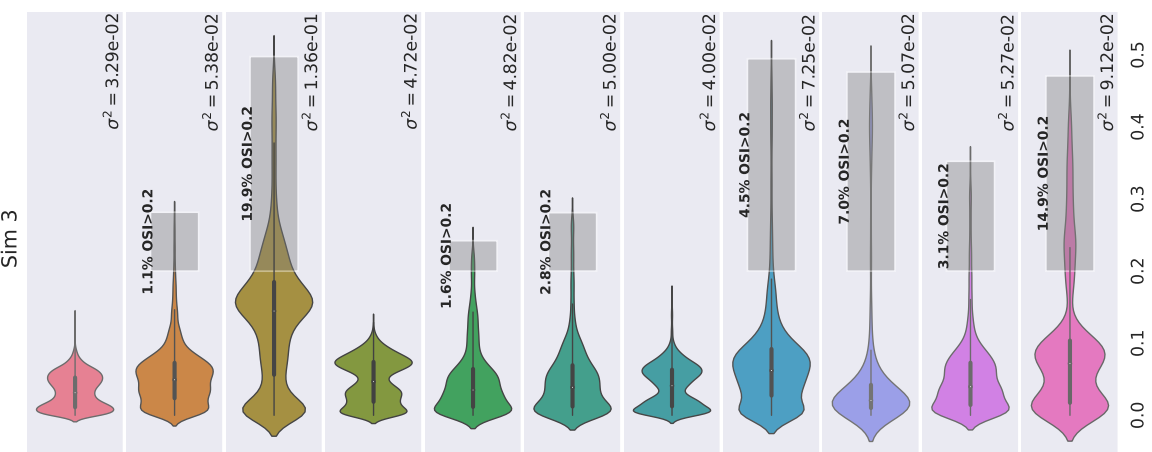

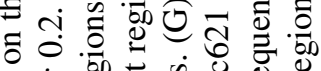

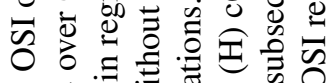

节卷

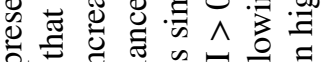

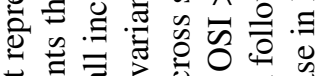

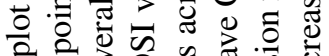

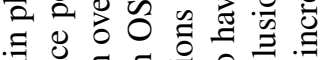
흏

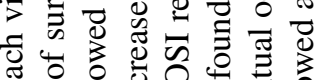

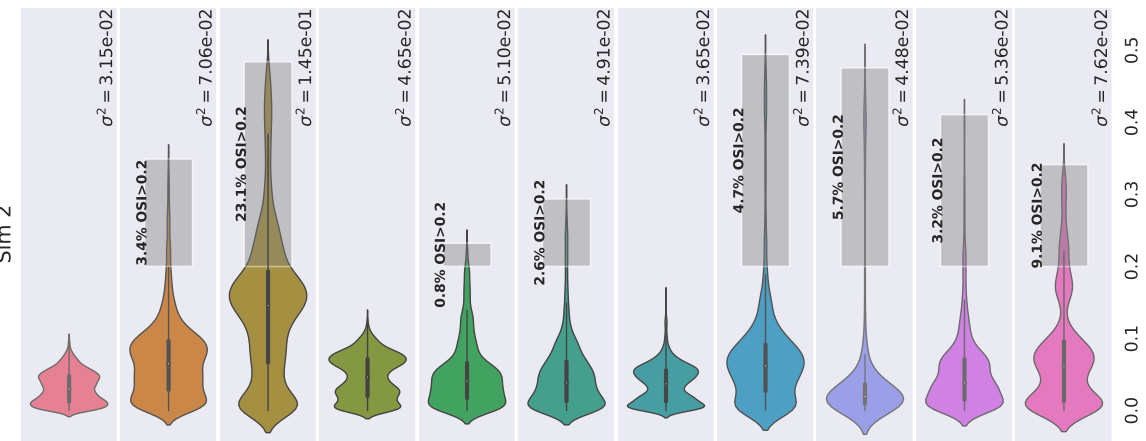

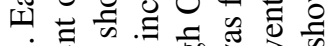
宇氙

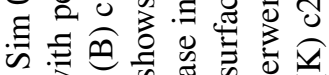
is

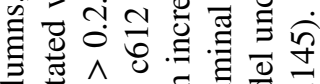

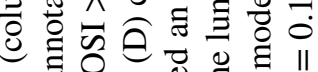

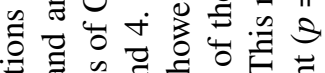

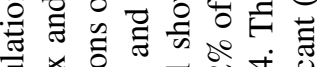
范 के

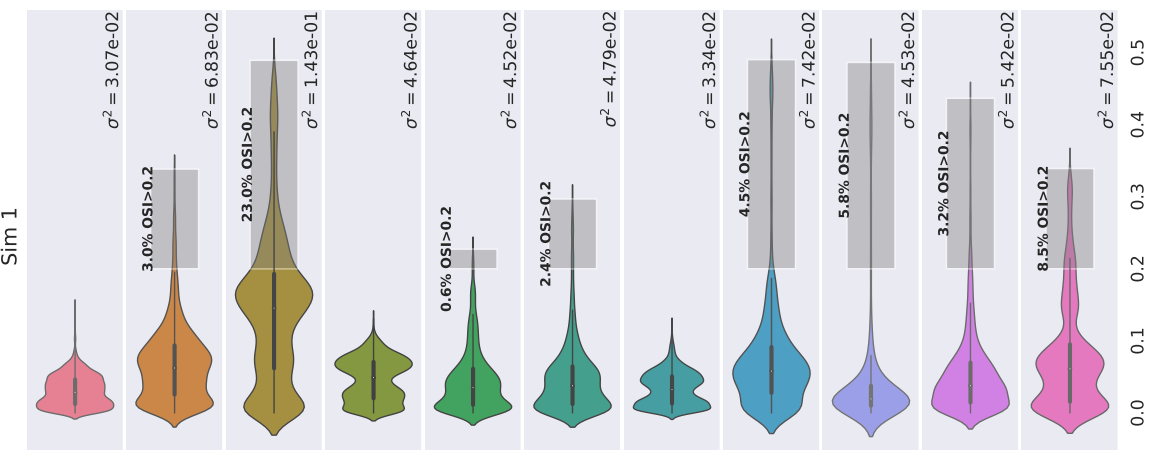

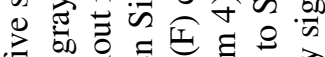

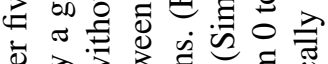
ठे

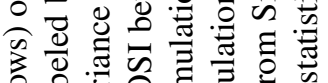

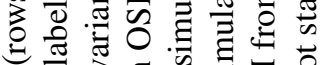

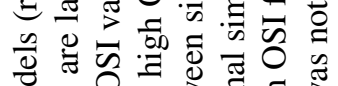
ชิ่

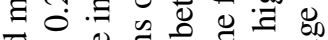

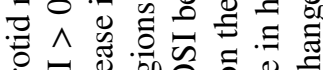
चั

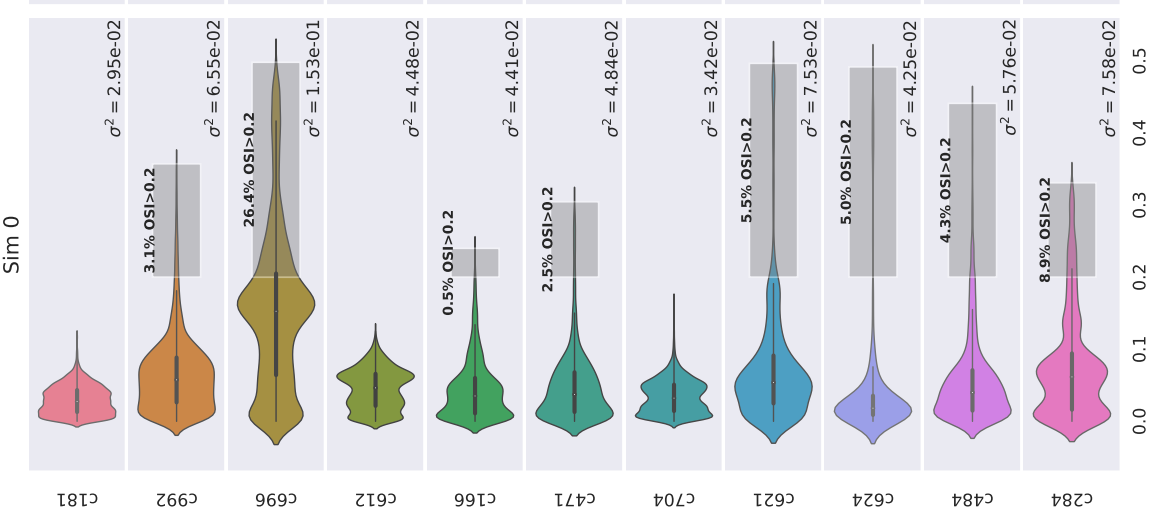
의.乌.

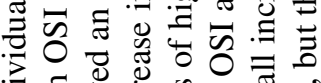

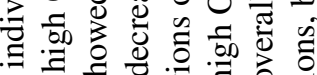
के क्ष

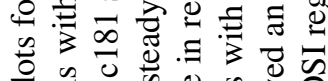

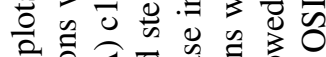

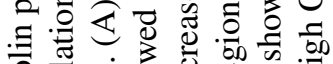

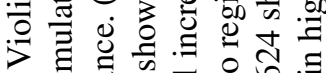
计陆

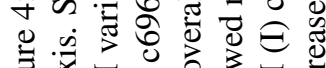

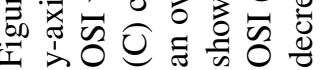


bioRxiv preprint doi: https://doi.org/10.1101/2022.02.04.479106; this version posted February 6, 2022. The copyright holder for this preprint (which was not certified by peer review) is the author/funder, who has granted bioRxiv a license to display the preprint in perpetuity. It is made available under aCC-BY-NC-ND 4.0 International license.

\section{An OSI-based Model To Assess Carotid Artery Stenosis}

\begin{tabular}{|c|c|c|c|c|c|c|c|}
\hline \multirow[b]{2}{*}{ ID } & \multirow[b]{2}{*}{ Points $_{i}\left(n_{i}\right)$} & \multicolumn{6}{|c|}{ Comparison of OSI Variance of the Initial and Final Simulations for Each Model } \\
\hline & & Points $_{f}\left(n_{f}\right)$ & $\% \mathrm{High} \mathrm{OSI}_{i}$ & $\% \mathrm{High} \mathrm{OSI}_{f}$ & Init. Var. $\left(\sigma_{i}^{2}\right)$ & Fin. Var. $\left(\sigma_{f}^{2}\right)$ & p-value \\
\hline c181 & $n_{i}=3463$ & $n_{f}=4055$ & $0.0 \%$ & $0.0 \%$ & $3.94 \times 10^{-4}$ & $5.92 \times 10^{-4}$ & $p=2.61 \times 10^{-64}$ \\
\hline c992 & $n_{i}=5074$ & $n_{f}=5493$ & $3.09 \%$ & $3.46 \%$ & $2.87 \times 10^{-3}$ & $3.04 \times 10^{-3}$ & $p=2.42 \times 10^{-6}$ \\
\hline c696 & $n_{i}=15375$ & $n_{f}=13808$ & $26.4 \%$ & $16.41 \%$ & $1.23 \times 10^{-2}$ & $8.81 \times 10^{-3}$ & $p=4.77 \times 10^{-40}$ \\
\hline c612 & $n_{i}=4379$ & $n_{f}=5005$ & $0.0 \%$ & $0.0 \%$ & $7.61 \times 10^{-4}$ & $1.10 \times 10^{-3}$ & $p=9.58 \times 10^{-88}$ \\
\hline c166 & $n_{i}=3477$ & $n_{f}=3598$ & $0.49 \%$ & $2.58 \%$ & $1.71 \times 10^{-3}$ & $2.65 \times 10^{-3}$ & $p=2.49 \times 10^{-14}$ \\
\hline c471 & $n_{i}=2988$ & $n_{f}=3088$ & $2.54 \%$ & $3.21 \%$ & $2.49 \times 10^{-3}$ & $2.80 \times 10^{-3}$ & $p=1.21 \times 10^{-2}$ \\
\hline c704 & $n_{i}=3664$ & $n_{f}=4306$ & $0.0 \%$ & $0.19 \%$ & $5.33 \times 10^{-4}$ & $2.01 \times 10^{-3}$ & $p \approx 0.00$ \\
\hline c621 & $n_{i}=4954$ & $n_{f}=6433$ & $5.49 \%$ & $5.94 \%$ & $6.92 \times 10^{-3}$ & $5.51 \times 10^{-3}$ & $p=2.18 \times 10^{-2}$ \\
\hline c624 & $n_{i}=3587$ & $n_{f}=3430$ & $5.02 \%$ & $8.8 \%$ & $6.36 \times 10^{-3}$ & $1.07 \times 10^{-2}$ & $p=1.22 \times 10^{-11}$ \\
\hline c484 & $n_{i}=4231$ & $n_{f}=4187$ & $4.25 \%$ & $3.61 \%$ & $3.94 \times 10^{-3}$ & $3.31 \times 10^{-3}$ & $p=1.45 \times 10^{-1}$ \\
\hline c284 & $n_{i}=3766$ & $n_{f}=4017$ & $8.9 \%$ & $13.44 \%$ & $5.33 \times 10^{-3}$ & $6.31 \times 10^{-3}$ & $p=3.56 \times 10^{-4}$ \\
\hline
\end{tabular}

Table 2

The table shows the percent increase in regions of high OSI between the initial simulation (Sim 0 in Figure 2) and final simulation (Sim 4 in Figure 2), as well as the associted change in variance of OSI between initial and final simulations. $P$-values were obtained by comparing the initial and final variance of OSI using Levene's test.

(2.59\% to $3.21 \%, p=0.0121)$ and $6621(5.49 \%$ to $5.94 \%$, $p=0.0218$ ) (Table 2). Larger increases in high OSI regions were also detected in c166 (0.49\% to $2.58 \%)$, c284 (8.9\% to $13.44 \%)$, and c624 (5.02\% to $8.8 \%)$, all of which reached statistical significance. These observations further supported the hypothesis that regions with high OSI values predispose arteries to atherosclerosis and associated luminal narrowing.

One model (c696) underwent morphological changes that led to an overall decrease in high OSI regions $(26.40 \%$ to $16.41 \%, p<<0.0001$ ) (Table 2) whereas another model (c484) trended in that direction but did not achieve statistical significance $(4.25 \%$ to $3.61 \%, p=0.145)$ (Table 2$)$. Qualitatively, these were seen as changes from bulbous morphologies to those that were more cylindrical.

We grouped these changes into two patterns due to the downstream morphological consequences on subsequent fluid dynamic simulations. (1) A statistically significant decrease, or no statistically significant change in OSI variance between simulations; or (2) a statistically significant increase in OSI variance between simulations. The latter category could be further refined by observing models with substantially elevated OSI (OSI > 0.2), which suggested substantial risk of atherosclerotic progression.

\section{Discussion}

Although low WSS and high OSI have been implicated in the progression of atherosclerosis, their predictive utility has remained somewhat limited [13]. This may be partially due to the challenge in predicting in vivo stenosis from computationally acquired hemodynamic metrics, as well as the fact that previous models reach spatial plaque prediction following a single simulation. The herein described methods may help overcome such limitations as they approach stenosis as an ongoing interplay between atherosclerosis and alterations in complex fluid flows. This research presents a dynamic landscape of aberrant fluid flows and highlights the effects of modeled stenosis on future fluid flows. This approach is the first to offer computational insight into an artery undergoing progressive stenosis, addressing whether the stenosis has a stabilizing or destabilizing effect on the flow patterns.

An example in which stenosis may stabilize flow can be seen in c696 (Figure 6). Although this model underwent stenosis, it showed an overall decrease in OSI variance and in high OSI regions. A similar trend is shown in c484, a model that was predicted to undergo further stabilization in later simulations. Conversely, the effect of stenosis may be destabilizing, as was observed in the other models, which showed an overall increase in OSI variance and, in some instances, a drastic increase in regions of high OSI (Figure 5). Thus, it is reasonable to consider that fluid flows represent an ever-changing landscape in the vessel lumen. As areas of high OSI emerge and undergo stenosis, new areas of high OSI may develop and even disappear. This study outlines and demonstrates a novel computational method for modeling the progression of stenosis at the carotid artery bifurcation based on OSI. Additionally, we offer an approach for quantifying its success and have demonstrated encouraging results that have directed our attention toward understanding atherosclerosis as a dynamic process modulated by the interplay of plaque geometry, vessel morphology, and hemodynamics based on the effects of the resulting stenoses.

The concept that flow disturbance is an important component in the initiation and progression of stenosis has been demonstrated several times. Specifically, arterial bifurcations throughout the vascular system are prone to the generation and progression of atherosclerosis, which eventually may lead to clinically significant stenosis. The vessel branching leads to flow instability through low and oscillatory stresses, which initiate and propagate the atherosclerotic cascade in at-risk individuals $[19,4,6,7]$. Despite the robust body of research relating arterial bifurcations with aberrant flow leading to atherosclerosis, their role in predictive modeling remains unclear. 
bioRxiv preprint doi: https://doi.org/10.1101/2022.02.04.479106; this version posted February 6, 2022. The copyright holder for this preprint (which was not certified by peer review) is the author/funder, who has granted bioRxiv a license to display the preprint in perpetuity. It is made available under aCC-BY-NC-ND 4.0 International license.

\section{An OSI-based Model To Assess Carotid Artery Stenosis}
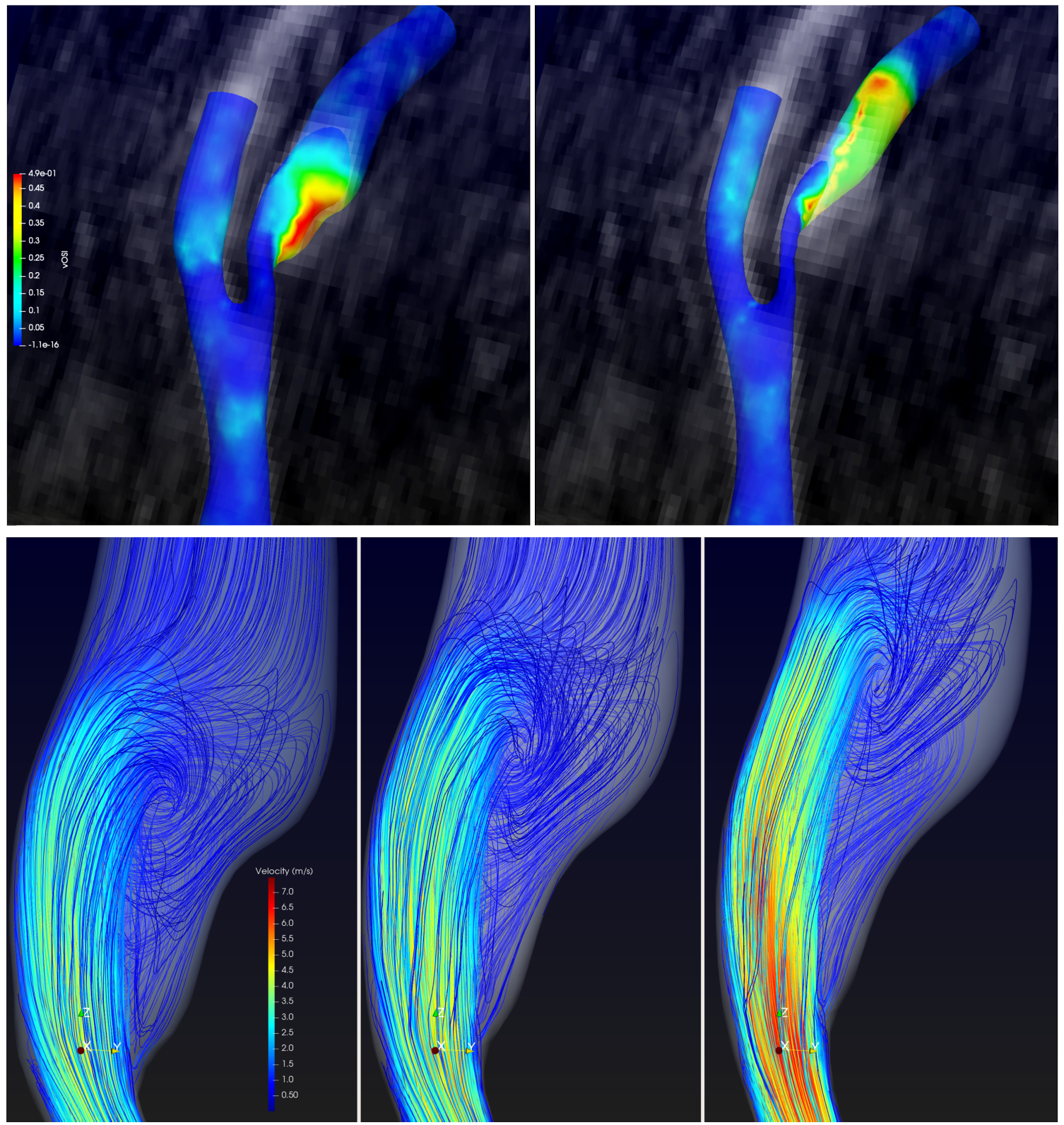

Figure 5: Impact of destabilizing stenosis on the surface and intraluminal space. The top panels show the luminal surface distribution of oscillatory shear index (OSI) before and after an iterative stenosis was performed. Warmer and cooler colors represent higher and lower OSI, respectively. Notice the migration of the region of high OSI more distally along the internal carotid artery (ICA). The bottom panels show the distal migration of unorganized fluid flow as the stenosis progresses. Warmer colors represent higher velocities. As expected, the velocity across the lesion increases as the stenosis progresses.

The methods described in this study may provide new foundations to begin modeling progressive stenosis; thus, representing more accurate modeling strategies as the in silico approach is refined and validated against in vivo data. For example, there are unresolved questions regarding the validation of the OSI $>0.2$ that was used to describe high OSI regions, but not for a threshold at which to perform in silico stenosis. This value was chosen based on biologicallyinformed reasoning and merely used as a quantitative indicator of destabilization; however, a more context-specific nuance could be introduced with the benefit of further statistical or biological analyses. Following model refinement and validation with in vivo clinical data are necessary to make any predictive conclusions.

One limitation of the herein proposed approach stems from the stenosis function itself. Although boundary layer thickness and wall stress calculations consider the vessel radius, our stenosis function does not, which may overestimate stenosis for smaller vessels and regions containing existing tight stenosis. Given the relatively similar size of the carotid arteries across our sample, we did not predict that substantial deviations should be considered. Nonetheless, this issue and the threshold-based stenosis functions will be the focus of future investigations. 
bioRxiv preprint doi: https://doi.org/10.1101/2022.02.04.479106; this version posted February 6, 2022. The copyright holder for this preprint (which was not certified by peer review) is the author/funder, who has granted bioRxiv a license to display the preprint in perpetuity. It is made available under aCC-BY-NC-ND 4.0 International license.

An OSI-based Model To Assess Carotid Artery Stenosis

c696_n
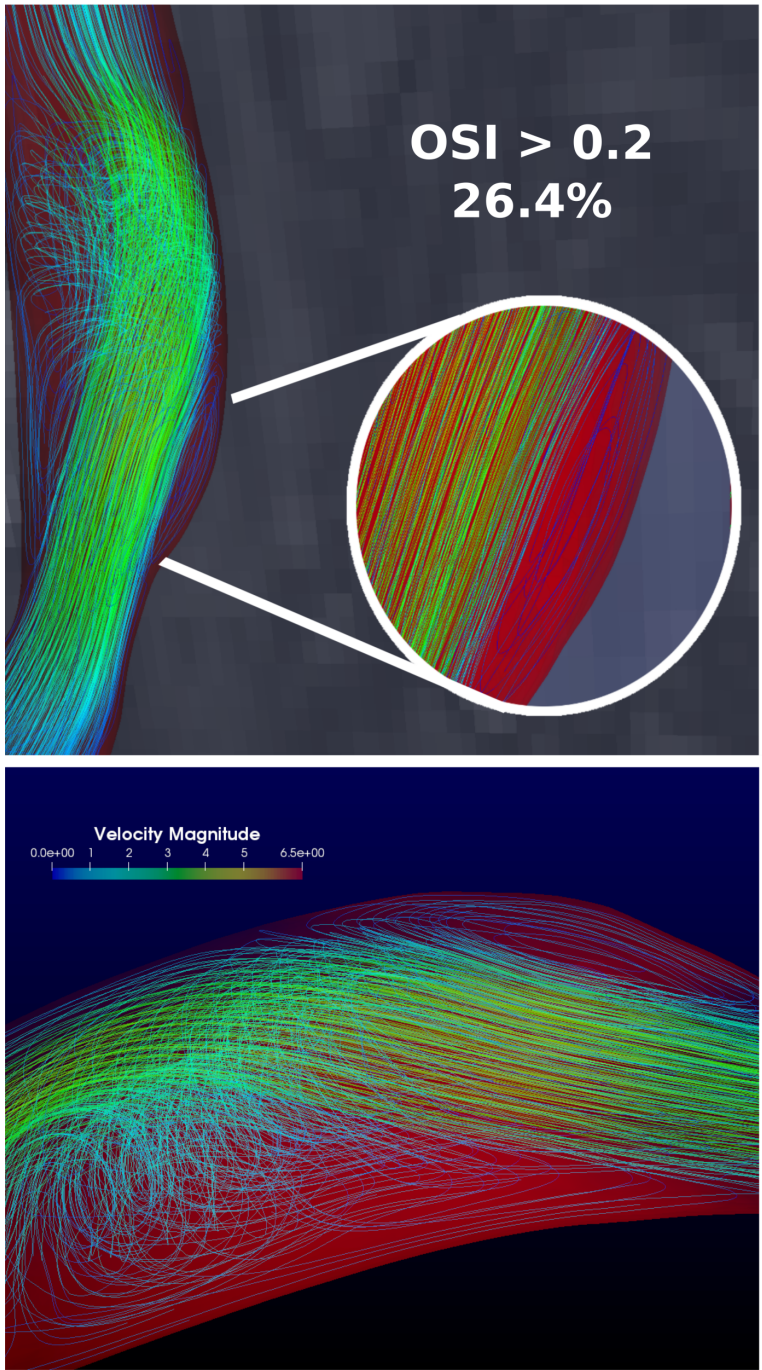

c696 4
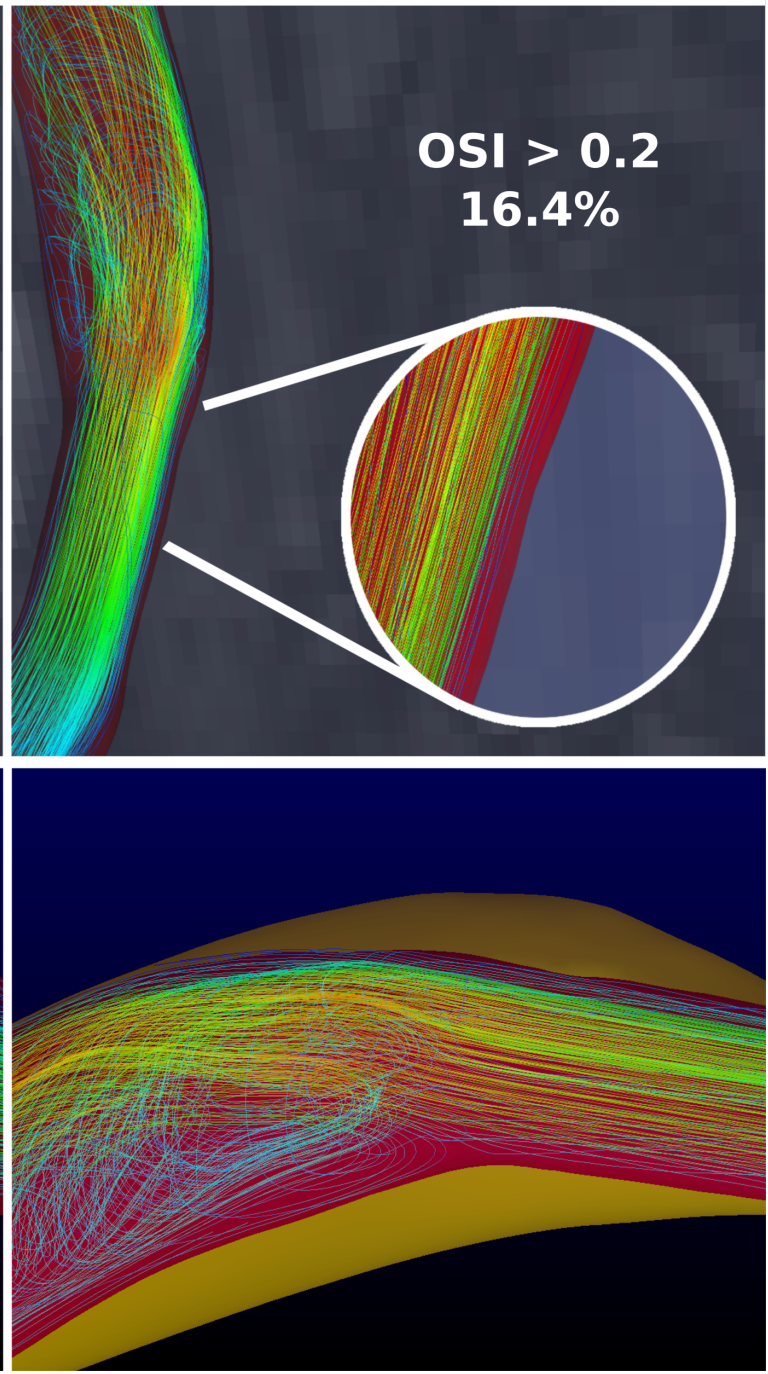

Figure 6: Representative example of stabilizing stenosis. The top panels show the native flow and following four iterations of stenosis with their associated percentage of luminal surface with high oscillatory shear index (OSI). Noteworthy is the resolution of the more disorganized fluid flow. The bottom panels shows the portion of the inner carotid artery (ICA) with native flow (bottom left) and following stenosis (bottom right). Additionally, the bottom right panel shows an overlay of the previously patent portion of the artery with a stabilizing flow pattern being noticeable across the region of stenosis.

As above mentioned, high OSI values were considered to be $>0.2$ based on evidence that suggests that elevated OSI leads to atherosclerotic-related gene expression and consequent increased risk of atherosclerosis [27, 28]. Therefore, we would expect that defining an OSI threshold for performing stenosis may lead to earlier morphological stabilization. For example, in c181 and c612 (Figure 2, panels 1 and 4) $0 \%$ of the luminal surface was found to have an OSI $>0.2$. If the threshold at which stenosis is performed is set to 0.2 , we would expect no morphological change of the luminal surface on subsequent simulations. Similarly, in models with regions of concentrated high OSI, we expect more focal stenoses along with possible changes in flow, thereby differing from those observed when a threshold is not used and which could be more similar to the vascular remodeling response seen in vivo [29].

While questions such as these are resolved or further refined and further analyses are conducted, we hope to develop an efficient computational method centered around the following main questions: (1) Does threshold modeling play a role in the propagation of in silico stenosis? (2) In atrisk patients, are there certain geometric configurations that can lead to inevitable progression of stenosis? (3) Can we identify specific features that make these vessels unique?

Our model represents a first attempt in answering these questions using patient-specific data. We hope to refine and validate this approach with the aim of creating a clinically applicable tool. An improved ability to predict the progression of stenosis in a patient-specific manner may represent a 
bioRxiv preprint doi: https://doi.org/10.1101/2022.02.04.479106; this version posted February 6, 2022. The copyright holder for this preprint (which was not certified by peer review) is the author/funder, who has granted bioRxiv a license to display the preprint in perpetuity. It is made available under aCC-BY-NC-ND 4.0 International license.

\section{An OSI-based Model To Assess Carotid Artery Stenosis}

profound leap forward in both this area of clinical decision making and in unraveling the complex relationship between biology, vessel morphology, and fluid dynamics.

\section{Conflicts of Interest}

The authors have no affiliations with or involvement in any organization or entity with any financial or non-financial interest in the subject matter described in this study.

\section{Acknowledgments}

Special thanks to Caron Rockman, MD, for her support and sponsorship of this research, as well as Glenn Jacobowitz, MD, and the Division of Vascular Surgery at NYU. Additionally, the author would like to acknowledge the developers of SimVascular, VMTK, and ParaView for allowing the open-source usage of their code.

\section{CRediT authorship contribution statement}

P Patalano: Conceptualization of this study, methodology, experimentation.

\section{References}

[1] D. Inzitari, M. Eliasziw, P. Gates, B. L. Sharpe, R. K. Chan, H. E. Meldrum, and H. J. Barnett. The causes and risk of stroke in patients with asymptomatic internal-carotid-artery stenosis. north american symptomatic carotid endarterectomy trial collaborators. The New England Journal of Medicine, 342(23):1693-1700, June 2000. ISSN 0028-4793. doi: 10.1056/NEJM200006083422302.

[2] Thomas G. Brott, Robert W. Hobson, George Howard, Gary S. Roubin, Wayne M. Clark, William Brooks, Ariane Mackey, Michael D. Hill, Pierre P. Leimgruber, Alice J. Sheffet, Virginia J. Howard, Wesley S. Moore, Jenifer H. Voeks, L. Nelson Hopkins, Donald E. Cutlip, David J. Cohen, Jeffrey J. Popma, Robert D. Ferguson, Stanley N. Cohen, Joseph L. Blackshear, Frank L. Silver, J.P. Mohr, Brajesh K. Lal, and James F. Meschia. Stenting versus endarterectomy for treatment of carotid-artery stenosis. New England Journal of Medicine, 363(1):11-23, July 2010. ISSN 0028-4793, 1533-4406. doi: 10.1056/NEJMoa0912321. URL http://www. nejm. org/doi/abs/10.1056/NEJMoa0912321.

[3] Alexander M. Nixon, Murat Gunel, and Bauer E. Sumpio. The critical role of hemodynamics in the development of cerebral vascular disease: A review. Journal of Neurosurgery, 112(6):12401253, June 2010. ISSN 0022-3085, 1933-0693. doi: 10.3171/2009. 10.JNS09759. URL https://thejns.org/view/journals/j-neurosurg/ 112/6/article-p1240.xml.

[4] Saurabh S. Dhawan, Ravi P. Avati Nanjundappa, Jonathan R. Branch, W. Robert Taylor, Arshed A. Quyyumi, Hanjoong Jo, Michael C. McDaniel, Jin Suo, Don Giddens, and Habib Samady. Shear stress and plaque development. Expert Review of Cardiovascular Therapy, 8(4):545-556, April 2010. ISSN 1744-8344. doi: 10.1586/erc.10.28.

[5] Umberto Morbiducci, Annette M. Kok, Brenda R. Kwak, Peter H. Stone, David A. Steinman, and Jolanda J. Wentzel. Atherosclerosis at arterial bifurcations: evidence for the role of haemodynamics and geometry. Thrombosis and Haemostasis, 115(3):484-492, March 2016. ISSN 2567-689X. doi: 10.1160/TH15-07-0597.

[6] Kyung-Sun Heo, Keigi Fujiwara, and Jun-ichi Abe. Shear stress and atherosclerosis. Molecules and Cells, 37(6):435-440, June 2014. ISSN 0219-1032. doi: 10.14348/molcells.2014.0078.

[7] Jeng-Jiann Chiu, Shunichi Usami, and Shu Chien. Vascular endothelial responses to altered shear stress: Pathologic implications for atherosclerosis. Annals of Medicine, 41(1):19-28,
January 2009. ISSN $0785-3890$, 1365-2060. doi: 10.1080/ 07853890802186921. URL http://www.tandfonline.com/doi/full/ 10.1080/07853890802186921.

[8] Michael A. Gimbrone and Guillermo García-Cardeña. Vascular endothelium, hemodynamics, and the pathobiology of atherosclerosis. Cardiovascular Pathology: The Official Journal of the Society for Cardiovascular Pathology, 22(1):9-15, February 2013. ISSN 18791336. doi: 10.1016/j.carpath.2012.06.006.

[9] Göran K. Hansson. Inflammation, atherosclerosis, and coronary artery disease. New England Journal of Medicine, 352(16): 1685-1695, April 2005. ISSN 0028-4793, 1533-4406. doi: 10. 1056/NEJMra043430. URL http://www. nejm.org/doi/abs/10.1056/ NEJMra043430.

[10] Jiyuan Tu, Kiao Inthavong, and Kelvin Kian Loong Wong. Computational Hemodynamics - Theory, Modelling and Applications. Biological and Medical Physics, Biomedical Engineering. Springer Netherlands : Imprint: Springer, Dordrecht, 1st ed. 2015 edition, 2015. ISBN 9789401795944.

[11] Keiichi Itatani, Shohei Miyazaki, Tokoki Furusawa, Satoshi Numata, Sachiko Yamazaki, Kazuki Morimoto, Rina Makino, Hiroko Morichi, Teruyasu Nishino, and Hitoshi Yaku. New imaging tools in cardiovascular medicine: computational fluid dynamics and $4 \mathrm{~d}$ flow mri. General Thoracic and Cardiovascular Surgery, 65(11):611-621, November 2017. ISSN 1863-6713. doi: 10.1007/s11748-017-0834-5.

[12] Celine Souilhol, Jovana Serbanovic-Canic, Maria Fragiadaki, Timothy J. Chico, Victoria Ridger, Hannah Roddie, and Paul C. Evans. Endothelial responses to shear stress in atherosclerosis: a novel role for developmental genes. Nature Reviews Cardiology, 17(1): 52-63, January 2020. ISSN 1759-5002, 1759-5010. doi: 10. 1038/s41569-019-0239-5. URL http://www. nature.com/articles/ s41569-019-0239-5.

[13] Veronique Peiffer, Spencer J. Sherwin, and Peter D. Weinberg. Does low and oscillatory wall shear stress correlate spatially with early atherosclerosis? a systematic review. Cardiovascular Research, 99(2):242-250, July 2013. ISSN 1755-3245, 0008-6363. doi: 10.1093/cvr/cvt044. URL https://academic. oup. com/cardiovascres/ article-lookup/doi/10.1093/cvr/cvt044.

[14] John Charonko, Satyaprakash Karri, Jaime Schmieg, Santosh Prabhu, and Pavlos Vlachos. In vitro, time-resolved piv comparison of the effect of stent design on wall shear stress. Annals of Biomedical Engineering, 37(7):1310-1321, July 2009. ISSN 0090-6964, 15739686. doi: 10.1007/s10439-009-9697-y. URL http://link. springer. com/10.1007/s10439-009-9697-y.

[15] Taylor Suess, Joseph Anderson, Laura Danielson, Katie Pohlson, Tyler Remund, Elizabeth Blears, Stephen Gent, and Patrick Kelly. Examination of near-wall hemodynamic parameters in the renal bridging stent of various stent graft configurations for repairing visceral branched aortic aneurysms. Journal of Vascular Surgery, 64(3):788796, September 2016. ISSN 1097-6809. doi: 10.1016/j.jvs.2015.04. 421.

[16] Huseyin Enes Salman, Burcu Ramazanli, Mehmet Metin Yavuz, and Huseyin Cagatay Yalcin. Biomechanical investigation of disturbed hemodynamics-induced tissue degeneration in abdominal aortic aneurysms using computational and experimental techniques. Frontiers in Bioengineering and Biotechnology, 7:111, 2019. ISSN 2296-4185. doi: 10.3389/fbioe.2019.00111.

[17] Jinah Hwang, Aniket Saha, Yong Chool Boo, George P. Sorescu, J. Scott McNally, Steven M. Holland, Sergei Dikalov, Don P. Giddens, Kathy K. Griendling, David G. Harrison, and Hanjoong Jo. Oscillatory Shear Stress Stimulates Endothelial Production of O 2 - from p47-dependent NAD(P)H Oxidases, Leading to Monocyte Adhesion. Journal of Biological Chemistry, 278(47):47291-47298, November 2003. ISSN 00219258. doi: 10.1074/jbc.M305150200. URL https: //linkinghub.elsevier.com/retrieve/pii/S0021925820760242.

[18] George P. Sorescu, Hannah Song, Sarah L. Tressel, Jinah Hwang, Sergey Dikalov, Debra A. Smith, Nolan L. Boyd, Manu O. Platt, Bernard Lassegue, Kathy K. Griendling, and Hanjoong Jo. Bone Morphogenic Protein 4 Produced in Endothelial Cells by Oscillatory Shear 
bioRxiv preprint doi: https://doi.org/10.1101/2022.02.04.479106; this version posted February 6, 2022. The copyright holder for this preprint (which was not certified by peer review) is the author/funder, who has granted bioRxiv a license to display the preprint in perpetuity. It is made available under aCC-BY-NC-ND 4.0 International license.

\section{An OSI-based Model To Assess Carotid Artery Stenosis}

Stress Induces Monocyte Adhesion by Stimulating Reactive Oxygen Species Production From a Nox1-Based NADPH Oxidase. Circulation Research, 95(8):773-779, October 2004. ISSN 0009-7330, 15244571. doi: 10.1161/01.RES.0000145728.22878.45. URL https: //www. ahajournals.org/doi/10.1161/01. RES.0000145728.22878.45.

[19] S. Glagov, C. Zarins, D. P. Giddens, and D. N. Ku. Hemodynamics and atherosclerosis. insights and perspectives gained from studies of human arteries. Archives of Pathology \& Laboratory Medicine, 112 (10):1018-1031, October 1988. ISSN 0003-9985.

[20] Amanda Sampaio Storch, Helena Naly Miguens Rocha, Vinicius Pacheco Garcia, Gabriel Matheus da Silva Batista, João Dario Mattos, Monique Opuszcka Campos, André Lopes Fuly, Antonio Claudio Lucas da Nóbrega, Igor Alexandre Fernandes, and Natália Galito Rocha. Oscillatory shear stress induces hemostatic imbalance in healthy men. Thrombosis Research, 170:119-125, October 2018. ISSN 00493848. doi: 10.1016/j.thromres.2018.08.019. URL https://linkinghub.elsevier.com/retrieve/pii/S0049384818304791.

[21] Peter F. Davies. Hemodynamic shear stress and the endothelium in cardiovascular pathophysiology. Nature Clinical Practice. Cardiovascular Medicine, 6(1):16-26, January 2009. ISSN 1743-4300. doi: 10.1038/ncpcardio1397.

[22] Ayla Hoogendoorn, Annette M. Kok, Eline M. J. Hartman, Giuseppe de Nisco, Lorena Casadonte, Claudio Chiastra, Adriaan Coenen, Suze-Anne Korteland, Kim Van der Heiden, Frank J. H. Gijsen, Dirk J. Duncker, Antonius F. W. van der Steen, and Jolanda J. Wentzel. Multidirectional wall shear stress promotes advanced coronary plaque development: comparing five shear stress metrics. Cardiovascular Research, 116(6):1136-1146, May 2020. ISSN 1755-3245. doi: $10.1093 / \mathrm{cvr} / \mathrm{cvz} 212$.

[23] Monika Colombo, Yong He, Anna Corti, Diego Gallo, Stefano Casarin, Jared M. Rozowsky, Francesco Migliavacca, Scott Berceli, and Claudio Chiastra. Baseline local hemodynamics as predictor of lumen remodeling at 1-year follow-up in stented superficial femoral arteries. Scientific Reports, 11(1):1613, January 2021. ISSN 20452322. doi: 10.1038/s41598-020-80681-8.

[24] D. N. Ku, D. P. Giddens, C. K. Zarins, and S. Glagov. Pulsatile flow and atherosclerosis in the human carotid bifurcation. positive correlation between plaque location and low oscillating shear stress. Arteriosclerosis (Dallas, Tex.), 5(3):293-302, June 1985. ISSN 02765047. doi: 10.1161/01.atv.5.3.293.

[25] Yiemeng Hoi, Bruce A Wasserman, Yuanyuan J Xie, Samer S Najjar, Luigi Ferruci, Edward G Lakatta, Gary Gerstenblith, and David A Steinman. Characterization of volumetric flow rate waveforms at the carotid bifurcations of older adults. Physiological Measurement, 31(3):291-302, March 2010. ISSN 0967-3334, 1361-6579. doi: 10.1088/0967-3334/31/3/002. URL https://iopscience.iop. org/article/10.1088/0967-3334/31/3/002.

[26] Claudio Chiastra, Stefano Morlacchi, Diego Gallo, Umberto Morbiducci, Rubén Cárdenes, Ignacio Larrabide, and Francesco Migliavacca. Computational fluid dynamic simulations of image-based stented coronary bifurcation models. Journal of the Royal Society, Interface, 10(84):20130193, July 2013. ISSN 1742-5662. doi: 10.1098/rsif.2013.0193.

[27] Ronny Amaya, Limary M. Cancel, and John M. Tarbell. Interaction between the stress phase angle (spa) and the oscillatory shear index (osi) affects endothelial cell gene expression. PloS One, 11(11): e0166569, 2016. ISSN 1932-6203. doi: 10.1371/journal.pone. 0166569.

[28] John J. Asiruwa, Aaron M. Propst, and Stephen P. Gent. Assessing Near-Wall Hemodynamics of Blood Flow in the Left Anterior Descending Segment of the Left Coronary Artery Using Computational Fluid Dynamics. In Volume 3: Biomedical and Biotechnology Engineering, page V003T04A023, Tampa, Florida, USA, November 2017. American Society of Mechanical Engineers. ISBN 9780791858363. doi: 10.1115/IMECE2017-71432. URL https://asmedigitalcollection.asme.org/IMECE/proceedings/ IMECE2017/58363/Tampa, \%20Florida, \%20USA/263594.
[29] Yiannis S. Chatzizisis, Ahmet Umit Coskun, Michael Jonas, Elazer R. Edelman, Charles L. Feldman, and Peter H. Stone. Role of endothelial shear stress in the natural history of coronary atherosclerosis and vascular remodeling: molecular, cellular, and vascular behavior. Journal of the American College of Cardiology, 49(25):2379-2393, June 2007. ISSN 1558-3597. doi: 10.1016/j.jacc.2007.02.059. 